\title{
6-Thioguanine Treatment in Inflammatory Bowel Disease: A Critical Appraisal by a European 6-TG Working Party
}

\author{
N.K.H. de Boer ${ }^{a}$ W. Reinisch ${ }^{b}$ A. Teml ${ }^{b}$ A.A. van Bodegraven ${ }^{a}$ \\ M. Schwab ${ }^{c}$ M. Lukas ${ }^{d}$ T. Ochsenkühn ${ }^{\text {e }}$ W. Petritsch ${ }^{f}$ P. Knoflach ${ }^{g}$ \\ S. Almer ${ }^{\text {h }}$ S.W. van der Merwe ${ }^{i}$ K.R. Herrlinger ${ }^{j} \quad$ J. Seiderer $^{\mathrm{e}}$ \\ H. Vogelsang ${ }^{\text {b }}$ C.J.J. Mulder ${ }^{a}$
}

\begin{abstract}
${ }^{a}$ Gastroenterology and Hepatology, VU University Medical Centre, Amsterdam, The Netherlands (representing the Dutch 6-TG working group); ${ }^{\mathrm{b}}$ Gastroenterology and Hepatology, Medical University Vienna, Vienna, Austria; ${ }^{\mathrm{c}}$ Dr. Margarete Fischer-Bosch-Institute of Clinical Pharmacology, Stuttgart, Germany; ${ }^{\mathrm{d}}$ Gastroenterology and Hepatology, Charles University, Prague, Czech Republic; ${ }^{\mathrm{e}}$ Gastroenterology and Hepatology, University Hospital Munich, Munich, Germany; ${ }^{f}$ Gastroenterology and Hepatology, Medical University Graz, Graz, Austria; ${ }^{9}$ Internal Medicine, Hospital of the Barmherzigen Schwestern, Wels, Austria; ${ }^{\mathrm{h}}$ Gastroenterology and Hepatology/IMK, Clinical Pharmacology/IMV, Linköping University, Linköping, Sweden; 'Gastroenterology, Unitas Hospital, Pretoria, South Africa; 'internal Medicine 1, Robert Bosch Krankenhaus, Stuttgart, Germany
\end{abstract}

\section{Key Words}

6-Thioguanine $\cdot$ Thiopurine $\cdot$ Inflammatory bowel disease $\cdot$ Crohn's disease and ulcerative colitis

\begin{abstract}
Recently, the suggestion to use 6-thioguanine (6-TG) as an alternative thiopurine in patients with inflammatory bowel disease (IBD) has been discarded due to reports about possible (hepato) toxicity. During meetings arranged in Vienna and Prague in 2004, European experts applying 6-TG further on in IBD patients presented data on safety and efficacy of 6-TG. After thorough evaluation of its risk-benefit ratio, the group consented that 6-TG may still be considered as a rescue drug in stringently defined indications in IBD, albeit restricted to a clinical research setting. As a potential indication for administering 6-TG, we delineated the requirement for maintenance therapy as well as intolerance and/or resistance to aminosalicylates, azathioprine, 6-mercaptopurine, meth-
\end{abstract}

otrexate and infliximab. Furthermore, indications are preferred in which surgery is thought to be inappropriate. The standard 6-TG dosage should not exceed $25 \mathrm{mg}$ daily. Routine laboratory controls are mandatory in short intervals. Liver biopsies should be performed after 6-12 months, three years and then three-yearly accompanied by gastroduodenoscopy, to monitor for potential hepatotoxicity, including nodular regenerative hyperplasia $(\mathrm{NRH})$ and veno-occlusive disease (VOD). Treatment with 6-TG must be discontinued in case of overt or histologically proven hepatotoxicity.

Copyright (C) 2006 S. Karger AG, Basel

\section{Introduction}

Inflammatory bowel disease (IBD) is an umbrella term for Crohn's disease (CD), ulcerative colitis (UC) and indeterminate colitis (IC). These entities are characterized by a chronic intestinal inflammation of relapsing clinical

\section{KARGER}

Fax +4161306 1234 E-Mail karger@karger.ch www.karger.com (c) 2006 S. Karger AG, Base 0012-2823/06/0731-0025\$23.50/0

Accessible online at: www.karger.com/dig
Walter Reinisch, MD

Department of Internal Medicine IV, Division of Gastroenterology and Hepatology Medical University of Vienna

Waehringer Guertel 18-20, AT-1090, Vienna (Austria)

Tel. +43 140400 4741, Fax +43140400 4735, E-Mail walter.reinisch@meduniwien.ac.at 


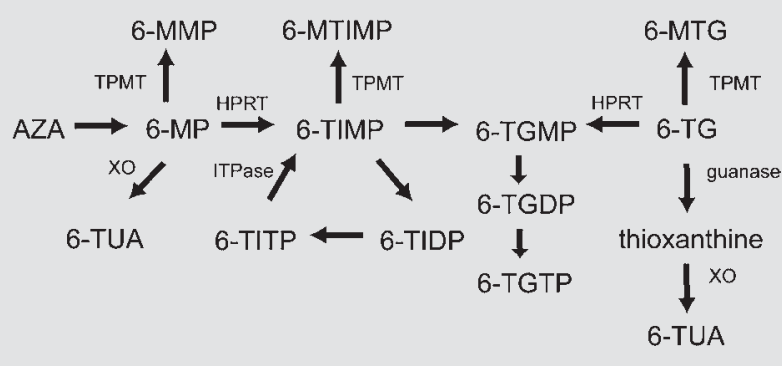

Fig. 1. Simplified thiopurine metabolism scheme. Azathioprine (AZA) is degraded to 6-mercaptopurine (6-MP). Thiopurine methyl transferase (TPMT) methylates 6-MP into 6-methylmercaptopurine (6-MMP). By hypoxanthine phosphoribosyl transferase, 6-MP is catalyzed to 6-thioinosine monophosphate (6-TIMP). Via two other (including hypoxanthine phosphoribosyl transferase) enzymatic steps the 6-thioguanine nucleotides (6-TGN) are ultimately generated. These 6-TGN consist of three phosphorylated forms: 6-thioguanosine monophosphate (6-TGMP), 6-thioguanosine diphosphate (6-TGDP) and 6-thioguanosine triphosphate (6-TGTP). 6-TIMP and 6-TGN may also be methylated by TPMT leading to 6-methyl-thioinosine monophosphate (6-MTIMP) and 6-methylthioguanine nucleotides (6-MTGN), respectively. In a cycle, 6-TIMP is phosphorylated to 6-thioinosine diphosphate (6-TIDP), subsequently to 6-thioinosine triphosphate (6-TITP) and ultimately back to 6-TIMP due to the inosine triphosphate pyrophosphatase (ITPase). When ITPase activity is impaired or lacking, 6-TITP accumulates. 6-Thioguanine (6-TG) is directly converted in 6-TGN but may also be methylated by TPMT leading to 6-methylthioguanine (6-MTG). The enzyme xanthine oxidase inactivates 6-MP by the formation of 6-thiouric-acid (6-TUA). Via an enzymatic step by guanase, $6-\mathrm{TG}$ is metabolized into thioxanthine which can be further degraded into 6-TUA by XO.

course. The aims of therapy are the relief of symptoms, the maintenance of clinical remission and prevention of complications of disease at an acceptable therapeutic risk-benefit ratio. In CD, thiopurines (azathioprine (AZA) and 6-mercaptopurine (6-MP)) represent the first-line maintenance drugs for steroid-dependent disease [1]. Methotrexate (MTX) is also effective in this indication, at least in patients in whom remission has been achieved by this agent. Infliximab is effective in CD patients refractory or intolerant to thiopurines or MTX [2, 3]. Concomitant immunosuppression with thiopurines or MTX is highly recommended to minimize the immunogenicity of infliximab in the setting of episodic treatment [4]. In the case of maintenance treatment with infliximab, the question of the role of concomitant immunosuppressants needs to be answered by more prospective data. In UC, 5-aminosalicylates (5-ASA) are the drugs of first choice to maintain remission in mild disease. In case of intolerance or drug resistance, AZA and 6-MP may be administered for maintenance of remission and steroid-sparing, respectively $[5,6]$. More recently, induction and maintenance of remission with infliximab in UC patients was demonstrated in two large trials $[7,8]$. The precise place of infliximab in the treatment of UC patients in daily clinical practice has yet to be determined; however, infliximab may become an attractive alternative in UC patients.

In recent years, the use of 6-thioguanine (6-TG) has been proposed as a rescue drug for AZA and 6-MP in IBD patients failing to tolerate or respond to standard thiopurines [9]. However, this suggestion has been discarded since 6-TG has been associated with the development of liver abnormalities in IBD patients [10]. An European working group of experts with experience on 6-TG in IBD has been constituted in Vienna in August 2004. We consented that 6-TG may still be considered an escape drug in strictly defined clinical situations in a clinical research setting and feel that further research is essential to outweigh the potential benefit of 6-TG to its toxicity profile. Here, we give a short overview of 6-TG literature in IBD and present a critical appraisal on 6-TG treatment in IBD as concluded from two meetings.

\section{Pharmacology of Thiopurines and the Emergence of 6-Thioguanine for Treating IBD}

AZA/6-MP are prodrugs which require bioactivation via hypoxanthine phosphoribosyl transferase (HPRT) to thiopurine nucleotides (thioinosine monophosphate or thioguanosine monophosphate, respectively) (fig. 1). The most important inactivating pathway is the S-methylation of thiopurines catalyzed by the thiopurine S-methyltransferase (TPMT), evidently because of alteration of the tautomeric form of the nucleobase. TPMT is involved at several steps in the complex metabolism of thiopurines, and the principal nucleotide metabolites are all substrates for human TPMT with similar kinetic parameters. Therefore, TPMT activity is inversely related to the accumulation of cellular 6-thioguanine nucleotides (6-TGN) which are thought to be the pharmacologically active compounds in cancer therapy [11]. More recently a further mechanism with regard to the immunosuppressive efficacy of thiopurine was proposed. The blockade of Rac1 activation is mediated via binding of the purine nucleotide 6-thioguanosine triphosphate to Rac1, consequently resulting in $\mathrm{T}$ cell apoptosis [12]. A possible advantage of 
6-TG administration is the direct conversion into 6-TGN (fig. 1) whereas in the case of AZA/6-MP a multi-enzymatic bioactivating process is required to ultimately form 6-TGN. Moreover, since TPMT is involved at several metabolic steps (fig. 1), it was assumed that the impact of TPMT is more pronounced using AZA/6MP than 6-TG. In the case of TPMT deficiency it has been clearly shown that non-methylators (1 up to 200 Caucasians [13]) are at risk to develop myelotoxicity under standard dosage of AZA/6-MP [14]. Nevertheless, myelotoxicity has also been reported under 6-TG treatment due to inherited TPMT deficiency [15]. On the other hand, very high TPMT activity enhances methylation of 6-MP to 6-methylmercaptopurine ribonucleotides (6-MMPR) and 6MMPR are potent inhibitors of the de novo purine synthesis, thereby participating to the immunosuppressive/ cytostatic potential of AZA/6-MP, in addition to the generated 6-TGN. Thus, it was proposed that AZA/6-MP is a two in one drug whereas 6-TG works predominately via formation of 6-TGNs. However, 6-TGNs are also methylated via TPMT and in vitro investigations indicate that methylated 6-TGN inhibit de novo purine synthesis as well. Moreover, the formation of methylated metabolites (MMPR) is of major interest since recently high levels of 6-MMPR were associated with dose-dependent AZA/6MP-related hepatotoxicity [16]. Although the underlying mechanism is still poorly understood this association was repeatedly shown in patients with IBD as well as in children with acute lymphoblastic leukemia and 6-MP therapy. To this end, mutations of the enzyme inosine triphosphatase (ITPase) resulting in alteration of ITPase activity have been related with AZA/6-MP adverse drug reactions like flu-like symptoms, rash and pancreatitis [17]. However, these data are still a matter of ongoing discussion since several contradictory results are published $[18,19]$. In the case of 6-TG, ITPase is not relevant since it is not involved in the metabolism of 6-TG (fig. 1).

Most of the clinical data on 6-TG stems from studies in hematological malignancies. In IBD treatment with 6TG was described as early as 1966 in three patients with UC. However, medication was discontinued prematurely due to intolerable neuro- and hepatotoxicity [20]. In more recent years, 6-TG has been considered an alternative treatment option in IBD patients who failed therapy with AZA or 6-MP due to refractoriness or intolerance (especially pancreatitis). In 2001, the benefit of 6-TG was suggested in a phenotypically distinct group of IBD patients who failed to attain disease control with traditional AZA and 6-MP therapy despite dose escalation [21]. These patients were unable to achieve therapeutic 6-TGN levels
( $\geq 235 \mathrm{pmol} / 8 \cdot 10^{8}$ red blood cells (RBC)) and developed excessive levels of potentially (hepato)toxic 6-MMPR upon 6-MP dose escalation. Dubinsky et al. [21] conducted an open-label pilot study in 10 of these phenotypically distinct CD patients to assess safety, tolerance and efficacy of 6-TG. In seven (70\%) of 10 patients response was achieved by administering 6-TG. Despite high levels of RBC 6-TGN $\left(>1,300 \mathrm{pmol} / 8 \cdot 10^{8} \mathrm{RBC}\right)$, patients did not develop myelotoxic or hepatotoxic events on a short term. Subsequently, several small-scaled uncontrolled open label studies followed in which AZA or 6-MP intolerant or refractory IBD patients were treated with 6-TG [22-28]. The majority of patients $(75-87 \%)$ were able to tolerate 6-TG treatment. This was recently confirmed in a larger study of 95 AZA or 6-MP intolerant patients using 6-TG for at least 1 year [29]. The most frequently observed side effects were gastrointestinal complaints, general malaise, allergic reactions and myelotoxicity. Pancreatitis was reported to be a rare adverse event. The use of 6-TG resulted in clinical improvement in a high percentage of this AZA or 6-MP intolerant group. Most recently, the results from an internet-based, international, multi-centric approach summarizing clinical data from 296 patients on the 6-TG therapy were shown, representing the largest population of IBD patients treated with 6-TG [30]. In 135 patients $(45.6 \%)$ treatment with 6-TG was continued at data entry for 93 weeks (range 2-207 weeks). Nevertheless, 161 patients stopped treatment due to adverse events $(44.1 \%)$, safety reasons $(21.7 \%)$ and treatment failure (24.4\%). Adverse events leading to treatment stop were mainly pain, nausea/vomiting, leukopenia and thrombopenia but only 7 patients discontinued treatment due to laboratory signs of hepatotoxicity, albeit the sensitivity of liver function parameters to indicate hepatotoxic side effects associated with 6-TG is limited. Data from randomized, controlled trials aiming to investigate for the safety and efficacy of 6-TG in IBD are not available.

\section{Hepatotoxicity of 6-Thioguanine in IBD Patients}

After the aforementioned promising reports, an article by Dubinsky et al. [10] at the end of 2003 reported the occurrence of nodular regenerative hyperplasia (NRH) of the liver in 16/26 (61.5\%) biopsies taken from 111 patients treated with 6-TG over a mean period of 9.1 months. Splenomegaly was reported in 4 of the 111 treated patients. The authors concluded that since the progression or reversibility of NRH is unknown 6-TG should not 
be considered as immunosuppressive therapy in IBD However, it should be stated that approximately $92 \%$ of the investigated IBD patients had used immunosuppressive medication (AZA or 6MP) before and that liver function disturbances had occurred in about $40 \%$ of them prior to the introduction of 6-TG. Since NRH has been described under therapy with AZA as well [31-38], the causative agent for the histopathological findings is diffcult to determine. Subsequently, the same working group published data on histological evaluations of liver biopsies from 37 patients, 20 of whom $(54.1 \%)$ had developed NRH under treatment with 6-TG [39]. The authors relativised their prior conclusion by stating that patients without therapeutic alternatives and without signs of NRH or liver fibrosis should periodically be rebiopsied when continuing therapy with 6-TG in absence of better therapeutic choices. Data stemming from a collaboration within our group confirmed the high frequency of hepatotoxicity in 6-TG-treated patients. In this trial $8 / 45$ patients $(17.8 \%)$ receiving 6-TG in a maximal daily dose $40-80 \mathrm{mg}$ for a treatment period of 8-119 weeks showed NRH and in the same number of patients equivocal patho-histological findings, possibly related to NRH were revealed [40]. It could be demonstrated that magnetic resonance imaging (MRI) may serve as a non-invasive technique to detect NRH with a sensitivity of $77 \%$ and a specificity of $72 \%$ [40]. Data from the online survey demonstrated that $31 / 60$ (51.7\%) liver biopsies of IBD patients treated with 6-TG had pathological findings [30]. In 11/38 (28.9\%) patients, whose liver samples had been stained with silver reticulin probable or definite NRH was diagnosed (number needed to harm (NNH) 3.5). In another approach, the significance of NRH by increasing the hepatic venous pressure gradient and even causing significant portal hypertension was shown in 6 out of 26 IBD patients treated with 6-TG [41]. In contrast, recent data on liver histology of 8 IBD patients using low dosages of 6-TG (18-21 mg daily) for a mean period of 23 months (16-36 months) revealed no histological abnormalities [42].

The exact pathogenesis of NRH remains to be elucidated but it is believed to be caused by disturbances of the microcirculation in the portal veins. Some aspects need to be emphasized on. As stated above NRH and similar hepatotoxic features have been described under therapy with AZA as well [31-38], albeit less common as compared to 6-TG. Based on the lack of comprehensive studies an accurate estimation on the frequency of $\mathrm{NRH}$ under AZA/6-MP treatment in IBD cannot be given. The high frequency of hepatotoxicity associated with 6-TG doses of $40-80 \mathrm{mg} /$ day may be attributed to the signifi- cantly enhanced levels of 6-TGN [42]. Interestingly, there is a clear predominance of hepatic lesions in male patients which raises the question of a genetic predisposition [43]. Additional different pharmacokinetic and metabolic characteristics or a different first-pass effect may play a role as well and future research is needed to elucidate these differences. New data from the United Kingdom acute lymphoblastic leukemia study suggest that hepatotoxicity and portal hypertension associated with 6-TG therapy in children may be progressive if essential hepatic architectural changes have occurred, even after discontinuation of the drug. However, this report is restricted to 6 children and conclusive results from adults on the natural course of NRH are missing [44].

\section{Constitution of a European Working Party on 6-Thioguanine in IBD}

A Dutch 6-TG working group was formed after the reports of hepatotoxicity on 6-TG treatment in 2003, in order to combine and discuss data and results of approximately 350 Dutch patients treated with 6-TG. Recently, safety and tolerability data of 95 of these patients were described [29]. Alongside this Dutch working group formation, an European collaboration was initiated consisting of largely university-based hospitals located in Amsterdam (representing the Dutch 6-TG working group), Graz, Linköping, Munich, Prague, Stuttgart, Wels and Vienna. Overall, several hundred patients have been treated with 6-TG by the members of the European working group.

\section{A Critical Appraisal of 6-Thioguanine Treatment in IBD}

A European 6-TG working party formulated the following expert-based guidelines for potential future 6-TG administration in IBD.

6-Thioguanine may be considered in IBD patients with requirement for maintenance therapy as well as intolerance and/or resistance to 5-aminosalicylates, AZA, 6-MP and MTX without an appropriate option for surgery (table 1). This includes an increased risk of shortbowel syndrome in patients with small bowel Crohn's disease or poor surgical candidates with increased risks of complications. In addition, infliximab should be administered before 6-TG therapy is initiated in IBD patients, however, at present the precise place of infliximab in the treatment of UC patients is only emerging. The ap- 
plication of 6-TG should be restricted to a clinical research setting and only after written informed consent providing information on its (hepato)toxic profile, particularly as IBD is an off-label indication of 6-TG use. The informed consent procedure stresses the clinical need for close follow-up and monitoring but also allows registration of patients. The group recommends that 6-TG should be administered in a standard dose, not exceeding $25 \mathrm{mg} /$ day. In the Netherlands, 6-TG is dosed at $0.3 \mathrm{mg} / \mathrm{kg}$ bodyweight resulting in three standard 6-TG dosages of 18, 21 and $24 \mathrm{mg}$. When IBD patients had to discontinue the previous AZA/6-MP use due to potential TPMT-related side effects (e.g. myelotoxicity or hematological abnormalities), TPMT deficiency should be definitively excluded. We recommend that 6-TG should not be used in pa-

Table 1. Definitions of resistance and intolerance to thiopurines

Definition of resistance

A lack of response defined by the inability to reach clinical remission as evaluated by global clinical assessment and the reduction of steroids to a dose of prednisolone or its equivalent $\leq 10 \mathrm{mg} / \mathrm{d}$ between weeks 12 and 24 after start of treatment with AZA/6-MP despite a dosage of AZA $\geq 2.0 / 6-\mathrm{MP} \geq 1.0 \mathrm{mg} / \mathrm{kg}$ body weight.

\section{Definition of intolerance}

An adverse event (AE) to thiopurines is defined as any reaction, side effect, or untoward event that occurs during the course of the treatment, whether or not the event is considered drug related. AEs will include events reported by the patient, as well as clinically significant abnormal findings on physical examination or laboratory evaluation. A new illness, symptom, or sign, a clinically significant laboratory abnormality, or worsening of a pre-existing condition or abnormality is considered an AE. A stable chronic conditions such as arthritis, which are present prior to clinical trial entry and do not worsen, are not considered AEs. Worsening of these conditions are AEs.

Table 2. Flowchart of controls (informed consent should be signed) tients with one or two mutant TPMT alleles since higher 6-TGN levels can be expected in spite of dose adjustment of thiopurines in these cases. 6-TG has to be withdrawn from patients resistant to therapy at the latest 6 months after initiation of therapy. A rigorous monitoring must be performed in all patients (table 2). The drug has to be discontinued in case of a twofold rise of at least one liver enzyme if at least possibly related to 6-TG use. The 6-TG dose must be discontinued when leukocyte counts are $\leq 3.5 \times 10^{9} / 1$. The 6 -TG dosage must be reduced when platelet counts are between 100,000 and 150,000 U/1. If platelet counts drop below 100,000 U/1 6-TG administration has to be stopped. In the latter case, a liver biopsy is mandatory as low platelets counts have been associated with NRH and portal hypertension. Given the documented sensitivity and specificity of specific MRI imaging [40], this noninvasive technique could additionally be considered for investigating patients during 6-TG treatment with unexplained laboratory abnormalities. Histological evaluation of the liver remains the golden standard for hepatotoxicity screening in 6-TG-treated patients.

The monitoring for hepatotoxicity must include first liver biopsy within 6 and 12 months after the initiation of 6-TG therapy. Subsequently, a liver biopsy must be performed after 3 years and, then after every 3 years of 6-TG use. Liver biopsy should be accompanied by gastroduodenoscopy. The group did not find consensus on taking a liver biopsy before the initiation of 6-TG treatment. The specimens should be evaluated by an experienced pathologist after staining with hematoxylin and eosin, (silver)reticulin and trichrome or optional chromotrope aniline blue [10]. The use of electron microscopy in evaluating (early) histological abnormalities is currently under investigation. It should be kept in mind that a liver biopsy has a small procedure-related risk of complications. The administration of 6-TG must be discontinued

\begin{tabular}{|c|c|}
\hline Parameters & At which moment? \\
\hline Complete blood count & baseline, 1, 2, 4, 8 and 12 weeks - every 3 months \\
\hline 6-Thioguanine nucleotides & optional to check patient compliance \\
\hline Alanine aminotranferase & baseline, $1,2,4,8$ and 12 weeks - every 3 months \\
\hline Aspartate aminotransferase & baseline, $1,2,4,8$ and 12 weeks - every 3 months \\
\hline Alkaline phosphatase & baseline, 1, 2, 4, 8 and 12 weeks - every 3 months \\
\hline Gamma-glutamyl transferase & baseline, $1,2,4,8$ and 12 weeks - every 3 months \\
\hline Bilirubin & baseline, 1, 2, 4, 8 and 12 weeks - every 3 months \\
\hline Liver biopsy + gastroduodenoscopy & $\begin{array}{l}\text { between } 6 \text { and } 12 \text { months; subsequently, } \\
\text { after } 3 \text { years and then every } 3 \text { years }\end{array}$ \\
\hline C-reactive protein (efficacy control) & baseline, $1,2,4,8$ and 12 weeks - every 3 months \\
\hline
\end{tabular}


in case histological abnormalities are found in the liver specimens. The measurement of 6-TGN levels in erythrocytes is only useful for determining patient compliance [45]. Contradictory results have been published about the potential teratogenic effects of 6-TG in case reports [4648]. Therefore, the use of 6-TG during pregnancy or lactation should be avoided.

\section{Conclusion}

Low-dose 6-thioguanine may still be considered as a rescue drug for maintenance of remission in IBD patients failing and/or intolerant to all evidence-based conventional therapies including mesalamine, AZA/6-MP, MTX and infliximab, and in whom surgery is thought to be inappropriate. Application has to be restricted to a clinical research setting. The reported incidence of nodular regenerative hyperplasia related to 6-TG use is of major concern and the number needed to harm equals 3.5. Therefore, any treatment protocols must include rigorous monitoring with regular liver biopsies. A specific MRI may be used as a noninvasive pre-biopsy screening tool. Further research is warranted before the use of 6-TG is discarded.

\section{Members of the European 6-TG Working Group}

Teml A, Harrer M, Feichtenschlager T, Vogelsang H, Reinisch W, Vienna (Austria); Knoflach P, Wels (Austria); Petritsch W, Graz (Austria); Lukas M, Chalupna P, Vavrova J, Prague (Czech Republic); Seiderer J, Ochsenkuhn T, Munich (Germany); Herrlinger KR, Schwab M, Stuttgart (Germany); Barrow PH, Johannesburg (South Africa); Van der Merwe SW, Pretoria (South Africa); Almer S, Linköping (Sweden); Van der Woude CJ, Rotterdam (The Netherlands), De Boer NKH, Van Bodegraven AA, Mulder CJJ, Amsterdam (The Netherlands).

\section{Dutch Participants of the 6-TG Working Group}

De Boer NKH, Terhaar sive Droste JS, Van Bodegraven AA, Mulder CJJ, Amsterdam; Festen HP, Den Bosch; Van Hogezand RA, Leiden; Spoelstra P, Leeuwarden; Gilissen LPL, Maastricht; Dijkstra G, Groningen; Engels LG, Bos LP, Sittard; Breumelhof R, Lam HGT, Utrecht; Thies JE, Den Hartog G, Arnhem; Westerveld BD, Vecht J, Zwolle; Van der Schaar PJ, Heerlen; Otten M, Amersfoort; Bac DJ, Rotterdam; De Jong DJ, Nijmegen; Derijks LJJ, Veldhoven, Van der Woude CJ, Rotterdam.

\section{Acknowledgement}

MS and KRH were supported by the Robert Bosch Foundation, Stuttgart, Germany.

\section{References}

1 Carter MJ, Lobo AJ, Travis SP: Guidelines for the management of inflammatory bowel disease in adults. Gut 2004;53(suppl 5):V1-V16.

2 Rutgeerts P, Feagan BG, Lichtenstein GR, Mayer LF, Schreiber S, Colombel JF, Rachmilewitz D, Wolf DC, Olson A, Bao W, Hanauer SB: Comparison of scheduled and episodic treatment strategies of infliximab in Crohn's disease. Gastroenterology 2004;126:402-413.

3 Hanauer SB, Feagan BG, Lichtenstein GR, Mayer LF, Schreiber S, Colombel JF, Rachmilewitz D, Wolf DC, Olson A, Bao W, Rutgeerts P: Maintenance infliximab for Crohn's disease: the ACCENT I randomised trial. Lancet 2002;359:1541-1549.

4 Rutgeerts P, Van Assche G, Vermeire S: Optimizing anti-TNF treatment in inflammatory bowel disease. Gastroenterology 2004; 126 : 1593-1610.

5 Al Hadithy AF, de Boer NK, Derijks LJ, Escher JC, Mulder CJ, Brouwers JR: Thiopurines in inflammatory bowel disease: pharmacogenetics, therapeutic drug monitoring and clinical recommendations. Dig Liver Dis 2005;37: 282-297.
6 Ardizzone S, Maconi G, Russo A, Imbesi V, Colombo E, Bianchi PG: Randomised, controlled trial, of azathioprine and 5-aminosalicylic acid for treatment of steroid-dependent ulcerative colitis. Gut 2005; in press.

7 Rutgeerts P, Feagan BG, Olson A, Johanns J, Travers S, Present D, Sands BE, Sandborn W, Olson A: A randomized placebo-controlled trial of infliximab therapy for active ulcerative colitis: Act I Trial. Gastroenterology 2005; 128 : A35-A36.

8 Sandborn W, Rachmilewitz D, Hanauer SB, Lichtensten GR, de Villiers WJ, Olson A, Johanns J, Travers S, Colombel JF: Infliximab induction and maintenance therapy for ulcerative colitis: the Act 2 Trial. Gastroenterology 2005;128:A36

9 de Jong D, Mulder CJ, van Sorge AA: Why measure thiopurine methyltransferase activity? Direct administration of 6-thioguanine might be the alternative for 6-mercaptopurine or azathioprine. Gut 2001;49:874.

10 Dubinsky MC, Vasiliauskas EA, Singh H, Abreu MT, Papadakis KA, Tran T, Martin P, Vierling JM, Geller SA, Targan SR, Poordad FF: 6-Thioguanine can cause serious liver injury in inflammatory bowel disease patients. Gastroenterology 2003;125:298-303.
11 Dervieux T, Blanco JG, Krynetski EY, Vanin $\mathrm{EF}$, Roussel MF, Relling MV: Differing contribution of thiopurine methyltransferase to mercaptopurine versus thioguanine effects in human leukemic cells. Cancer Res 2001;61: 5810-5816.

12 Tiede I, Fritz G, Strand S, Poppe D, Dvorsky R, Strand D, Lehr HA, Wirtz S, Becker C, Atreya R, Mudter J, Hildner K, Bartsch B, Holtmann M, Blumberg R, Walczak H, Iven H, Galle PR, Ahmadian MR, Neurath MF: CD28-dependent Rac1 activation is the molecular target of azathioprine in primary human CD4+ T lymphocytes. J Clin Invest 2003; 111:1133-1145.

13 Schaeffeler E, Fischer C, Brockmeier D, Wernet D, Moerike K, Eichelbaum M, Zanger UM, Schwab M: Comprehensive analysis of thiopurine S-methyltransferase phenotype-genotype correlation in a large population of GermanCaucasians and identification of novel TPMT variants. Pharmacogenetics 2004; 14:407417. 
14 Colombel JF, Ferrari N, Debuysere H, Marteau P, Gendre JP, Bonaz B, Soule JC, Modigliani R, Touze Y, Catala P, Libersa C, Broly F: Genotypic analysis of thiopurine S-methyltransferase in patients with Crohn's disease and severe myelosuppression during azathioprine therapy. Gastroenterology 2000;118: 1025-1030.

15 McBride KL, Gilchrist GS, Smithson WA, Weinshilboum RM, Szumlanski CL: Severe 6thioguanine-induced marrow aplasia in a child with acute lymphoblastic leukemia and inherited thiopurine methyltransferase deficiency. J Pediatr Hematol Oncol 2000;22:441-445.

16 Dubinsky MC, Lamothe S, Yang HY, Targan SR, Sinnett D, Theoret Y, Seidman EG: Pharmacogenomics and metabolite measurement for 6-mercaptopurine therapy in inflammatory bowel disease. Gastroenterology 2000;118: 705-713.

17 Marinaki AM, Ansari A, Duley JA, Arenas M, Sumi S, Lewis CM, Shobowale-Bakre e, Escuredo E, Fairbanks LD, Sanderson JD: Adverse drug reactions to azathioprine therapy are associated with polymorphism in the gene encoding inosine triphosphate pyrophosphatase (ITPase). Pharmacogenetics 2004;14:181-187.

18 Gearry RB, Roberts RL, Barclay ML, Kennedy MA: Lack of association between the ITPA 94C $>$ A polymorphism and adverse effects from azathioprine. Pharmacogenetics 2004; 14:779-781.

19 van Dieren JM, van Vuuren AJ, Kusters JG, Nieuwenhuis EE, Kuipers EJ, van der Woude CJ: ITPA genotyping is not predictive for the development of side effects in AZA treated inflammatory bowel disease patients. Gut 2005; 54:1664.

20 Bean, RHD: Treatment of ulcerative colitis with antimetabolites. Br Med J 1966;1:10811084.

21 Dubinsky MC, Hassard PV, Seidman EG, Kam LY, Abreu MT, Targan SR, Vasiliauskas EA: An open-label pilot study using thioguanine as a therapeutic alternative in Crohn's disease patients resistant to 6-mercaptopurine therapy. Inflamm Bowel Dis 2001;7:181-189.

22 Herrlinger KR, Kreisel W, Schwab M, Schoelmerich J, Fleig WE, Ruhl A, Reinshagen M, Deibert P, Fellermann K, Greinwald R, Stange EF: 6-thioguanine-efficacy and safety in chronic active Crohn's disease. Aliment Pharmacol Ther 2003; 17:503-508.

23 Herrlinger KR, Deibert P, Schwab M, Kreisel W, Fischer C, Fellermann K, Stange EF: Remission maintenance by tioguanine in chronic active Crohn's disease. Aliment Pharmacol Ther 2003; 17:1459-1464.

24 Bonaz B, Boitard J, Marteau P, Lemann M, Coffin B, Flourie B, Belaiche J, Cadiot G, Metman EH, Cortot A, Colombel JF: Tioguanine in patients with Crohn's disease intolerant or resistant to azathioprine/mercaptopurine. Aliment Pharmacol Ther 2003;18:401-408.
25 Derijks LJ, de Jong DJ, Gilissen LP, Engels LG, Hooymans PM, Jansen JB, Mulder CJ: 6Thioguanine seems promising in azathioprineor 6-mercaptopurine-intolerant inflammatory bowel disease patients: a short-term safety assessment. Eur J Gastroenterol Hepatol 2003; 15:63-67.

26 Dubinsky MC, Feldman EJ, Abreu MT, Targan SR, Vasiliauskas EA: Thioguanine: a potential alternate thiopurine for IBD patients allergic to 6-mercaptopurine or azathioprine. Am J Gastroenterol 2003;98:1058-1063.

27 Teml A, Schwab M, Harrer M, Miehsler W, Schaeffeler E, Dejaco C, Mantl M, Schneider B, Vogelsang H, Reinisch W: A prospective, open-label trial of 6-thioguanine in patients with ulcerative or indeterminate colitis. Scand J Gastroenterol 2005;40:1205-1213.

28 Teml A, Dejaco C, Miehsler W, Harrer M, Vogelsang $\mathrm{H}$, Reinisch W: Long-term efficacy of 6-thioguanine in patients with inflammatory bowel disease. Gut 2005;53(suppl VI):A229.

29 de Boer NK, Derijks LJ, Gilissen LP, Hommes DW, Engels LG, de Boer SY, den Hartog G, Hooymans PM, Makelburg AB, Westerveld BD, Naber AH, Mulder CJ, de Jong DJ: On tolerability and safety of a maintenance treatment with 6-thioguanine in azathioprine or 6mercaptopurine intolerant IBD patients. World J Gastroenterol 2005; 11:5540-5544.

30 Teml A, Hommes D, Almer S, Lukas M, Feichtenschlager T, Florin T, Ochsenkuhn T, Petritsch W, Bokemeyer B, Kreisel W, Herrlinger K, Knoflach P, Roblin X, Klugmann T, Herfarth H, Schwab M, Perdarnig M, Reinisch W: The 6-thioguanine (6-TG) online survey platform: an international, multi-centric approach to summarize clinical data collected during the use of 6-TG in patients with inflammatory bowel disease (IBD). Gut 2005;54(suppl VII): A44.

31 Buffet C, Cantarovitch M, Pelletier G, Fabre M, Martin E, Charpentier B, Etienne JP, Fries D: Three cases of nodular regenerative hyperplasia of the liver following renal transplantation. Nephrol Dial Transplant 1988;3:327330.

32 Russmann S, Zimmermann A, Krahenbuhl S, Kern B, Reichen J: Veno-occlusive disease, nodular regenerative hyperplasia and hepatocellular carcinoma after azathioprine treatment in a patient with ulcerative colitis. Eur J Gastroenterol Hepatol 2001; 13:287-290.

33 Naber AH, Van Haelst U, Yap SH: Nodular regenerative hyperplasia of the liver: an important cause of portal hypertension in non-cirrhotic patients. J Hepatol 1991;12:94-99.

34 Daniel F, Cadranel JF, Seksik P, Cazier A, Duong Van Huyen JP, Ziol M, Coutarel P, Loison P, Jian R, Marteau P: Azathioprine induced nodular regenerative hyperplasia in IBD patients. Gastroenterol Clin Biol 2005;29:600603.

35 Jones MC, Best PV, Catto GR: Is nodular regenerative hyperplasia of the liver associated with azathioprine therapy after renal transplantation? Nephrol Dial Transplant 1988;3: 331-333.
36 Haboubi NY, Ali HH, Whitwell HL, Ackrill P: Role of endothelial cell injury in the spectrum of azathioprine-induced liver disease after renal transplant: light microscopy and ultrastructural observations. Am J Gastroenterol 1988; 83:256-261.

37 Fonseca V, Havard CW: Portal hypertension secondary to azathioprine in myasthenia gravis. Postgrad Med J 1988;64:950-952.

38 Gane E, Portmann B, Saxena R, Wong P, Ramage J, Williams R: Nodular regenerative hyperplasia of the liver graft after liver transplantation. Hepatology 1994;20:88-94.

39 Shastri S, Dubinsky MC, Fred PF, Vasiliauskas EA, Geller SA: Early nodular hyperplasia of the liver occurring with inflammatory bowel diseases in association with thioguanine therapy. Arch Pathol Lab Med 2004;128:49-53.

40 Seiderer J, Zech CJ, Reinisch W, Lukas M, Diebold J, Wrba F, Teml A, Chalupna P, Stritesky J, Schoenberg SO, Schima W, Goke B, Ochsenkuhn T: A multicenter assessment of liver toxicity by MRI and biopsy in IBD patients on 6-thioguanine. J Hepatol 2005;43: 303-309.

41 Ferlitsch A, Teml A, Reinisch W, Peck-Radosavljevic M, Wrba F, Ulbrich G, Vogelsang $\mathrm{H}$ : 6-thioguanine associated nodular regenerative hyperplasia in patients with inflammatory bowel disease may induce portal hypertension. Gut 2005;54(suppl VII):A45.

42 de Boer NK, Mulder CJ, van Bodegraven AA: Nodular regenerative hyperplasia and thiopurines: the case for level-dependent toxicity. Liver Transpl 2005;11:1300-1301.

43 Katzka DA, Saul SH, Jorkasky D, Sigal H, Reynolds JC, Soloway RD: Azathioprine and hepatic venocclusive disease in renal transplant patients. Gastroenterology 1986;90:446454

44 De Bruyne R, Portmann B, Samyn M, Bansal S, Knisely A, Mieli-Vergani G, Dhawan A: Chronic liver disease related to 6-thioguanine in children with acute lymphoblastic leukaemia. J Hepatol 2005. Epub ahead of print.

45 Herrlinger KR, Fellermann K, Fischer C, Kreisel W, Deibert P, Schoelmerich J, Fleig WE, Ruhl A, Reinshagen M, Greinwald R, Stange EF, Schwab M: Thioguanine-nucleotides do not predict efficacy of tioguanine in Crohn's disease. Aliment Pharmacol Ther 2004;19: 1269-1276.

46 Lilleyman JS, Hill AS, Anderton KJ: Consequences of acute myelogenous leukemia in early pregnancy. Cancer 1977;40:1300-1303.

47 Artlich A, Moller J, Tschakaloff A, Schwinger E, Kruse K, Gortner L: Teratogenic effects in a case of maternal treatment for acute myelocytic leukaemia: neonatal and infantile course. Eur J Pediatr 1994; 153:488-491.

48 De Boer N, van Elburg R, Wilhelm A, Remmink A, van Vugt J, Mulder C, van Bodegraven A: 6-Thioguanine for Crohn's disease during pregnancy: thiopurine metabolite measurements in both mother and child. Scand J Gastroenterol 2005;40:1374-1377. 